\title{
Exposure to Cigarette Smoke Disrupts CCL20-Mediated Antimicrobial Activity in Respiratory Epithelial Cells
}

\author{
Mardi A. Crane-Godreau*, Matthew A. Maccani, Susan K. Eszterhas, Sandra L. Warner, \\ James A. Jukosky and Steven Fiering
}

Department of Microbiology \& Immunology, Dartmouth Medical School, Lebanon, NH 03756, USA

\begin{abstract}
Cigarette smoke (CS) exposure is known to increase infection rates, but the mechanisms are not well understood. These studies tested the hypothesis that CS exposure would impair antimicrobial activity of apical conditioned media from human airway (BEAS-2B) cultures by reducing induction and release of the antimicrobial peptide CCL20. BEAS-2B cultures were exposed to CS extract and assayed for temporal and physical characteristics of release as well as for antimicrobial activity. E. coli were exposed to Beas-2B-conditioned media (BCM) and subsequent bacterial colonies were enumerated. In time course studies TLR-agonist-induced CCL20 transcription and release were rapid, of short duration and release was consistently targeted to the apical/luminal compartment. Cells treated with CS extract had diminished release of CCL20 under both constitutive and toll-like receptor (TLR) agonist stimulating conditions. Exposure of the cells to CS significantly reduced the antimicrobial activity in BCM and neutralizing antibodies to CCL20 brought antibacterial activity back to baseline levels demonstrating that antimicrobial activity in this culture system was primarily attributable to CCL20. These studies add to the understanding of CCL20 as a mucosal antimicrobial and improve insight into a likely mechanism linking infection to CS exposure.
\end{abstract}

Keywords: Innate immune, mucosal immune, cigarette smoke.

\section{INTRODUCTION}

The observation that exposure to primary and/or second hand cigarette smoke (CS) increases susceptibility to infection is confirmed by research [1-3]. In infants, CS exposure is associated with increased incidence of severe cases of respiratory syncytial virus induced bronchiolitis with lower $\mathrm{O}_{2}$ saturation than unexposed infants [4]. Exposure to CS has also been identified as a predicator of acute life threatening events (ALTE) in infants, a condition that may be related to sudden infant death syndrome (SIDS) [5]. Children exposed to second hand smoke are at increased risk for upper respiratory tract infections including otitis media and significant ultrastructural changes to adenoid tissues relative to non-CS exposed children [6]. Interestingly, CS exposure is associated with infections at mucosal sites throughout the body. For example, risk factors for invasive meningococcal disease (IMD) includes any exposure to CS (primary or passive) in children and young adults [7]. In women, smoking is a significant risk factor for bacterial vaginosis [8], recurring human papillomavirus (HPV) infection [9] and for preterm labor [10] and the latter is associated with recurring urinary tract infections and bacterial vaginosis $[10,11]$. Acquisition of nosocomial bacteremia, originating from catheter-associated urinary tract infections, has also been linked to cigarette use within the past five years [12]. Smokers also incur a two- to four-fold

*Address correspondence to this author at the Department of Microbiology \& Immunology, Dartmouth Medical School, HB 7936, 1 Medical Center Dr., Lebanon, NH 03756, USA; Tel: 603-653-9970; Fax: 603-653-9952;

E-mail: mardi.crane@dartmouth.edu increased risk of invasive pneumococcal disease, increased severity and risk for influenza and an increased risk of acquiring tuberculosis [1].

CS associated infection originates at mucosal sites where innate immunity plays a primary role in defense against microbial invasion. Primary aspects of innate immune protection against infection include physical and chemical barriers comprised of skin, mucosal epithelium, cilia and cellular secretions including mucus and antimicrobial agents [13]. The production of antimicrobial secretions including defensins, lactoferrin, secretory leukoprotease inhibitor (SLPI), lysozyme, and other defensin-like peptides, as well as a host of other proteins by mucosal epithelial cells, is stimulated through a system of pattern recognition receptors (PRR), including TLR, that monitor for, and respond to, the presence of normal flora and pathogenic microbes [14-17]. It is proposed that synergistic interactions among antimicrobial peptides enhance antimicrobial properties at mucosal surfaces [16]; these interactions are thought to be important in the complex regulation of dynamic microbial ecosystems found at mucosal surfaces.

The linkage of microbial surveillance to adaptive immune responses depends on the production and release of cytokines and chemokines $[13,18]$. Our studies have focused on CCL20, a peptide with both chemotactic and antimicrobial activity. Chemokine ligand 20 (CCL20) (reviewed by Schutyser) [19] is released by epithelial cells of the digestive, airway and reproductive tracts under both constitutive and inflammatory conditions [20-22] stimulating the migration of B-cells [23], immature dendritic cells [24], and a subset of memory $\mathrm{T}$ cells [25]. Consistent with the 
discovery that it shares significant homology with betadefensins, CCL20 is antimicrobial against Gram negative and Gram positive bacteria as well as yeast [26]. This is due to an ability to rapidly permeabilize microbial membranes [27]. Recent studies have also demonstrated that CCL20 has antiviral properties against vaccinia virus [28].

In addition to the association between CS exposure and infections, there are multiple reports of disregulation of CCL20 in human diseases such as chronic obstructive pulmonary disease (COPD) [29], inflammatory bowel disease (IBD) [30] and psoriasis [31] that are also epidemiologically associated with CS exposure [32-34]. These studies led us to determine if this peptide is somehow affected by CS exposure. Here we report the investigation of the effect of CS exposure on BEAS-2B cells, a human bronchial epithelial cell line, to determine if CS exposure results in disruption of antimicrobial innate immune protection. Specifically, we tested the hypothesis that CS exposure suppresses the production and secretion of CCL20 in BEAS-2B cells and thereby results in reduced antimicrobial activity of these cells.

\section{MATERIALS AND METHODS}

Cell culture. Human bronchial epithelial cells, BEAS-2B (ATCC, Manassas, VA) were prepared in antibiotic-free DMEM/F12 supplemented with 10\% FBS and L-glutamine (Mediatech/Cellgro, Manassas, VA), plated on collagencoated NUNC cell culture inserts with media in both the apical and basolateral compartments and incubated at $37^{\circ} \mathrm{C}$ with 5\% CO2 and humidity. After 24 hours, media were removed from the apical chambers. Cells were then grown at the air-surface interface with $500 \mu \mathrm{L}$ antibiotic-free medium only in the basolateral compartment until time of treatment. Medium was changed at 24 to 48 hour intervals.

Cigarette Smoke Extract (CSE). CSE was prepared using a modified method of Carp and Janoff [35] specifically by passing the smoke from nine puffs from one cigarette through $100 \mathrm{~mL}$ of PBS and by allowing suspended smoke in the flask to settle for 15 minutes prior to filtration through a 0.2 micron filter and stored at $4^{\circ} \mathrm{C}$. Control filtered PBS was prepared in the same manner as CSE except using a clean aspiration system and no cigarette. CSE was prepared fresh for each experiment from commercially available unfiltered cigarettes.

Experimental CSE, LTA and LPS exposures. At day 4 of cell culture, residual liquid was removed from the apical compartment by aspiration. The apical surface was treated with $100 \mu \mathrm{L}$ of $1 \mathrm{x}$ CSE or $100 \mu \mathrm{L}$ of $1 \mathrm{x}$ control PBS for 90 minutes at $37^{\circ} \mathrm{C}$. Following treatment, the CSE or PBS solution was aspirated, and the surface of each apical compartment was gently rinsed with 1x PBS. Lipoteichoic acid (LTA) or Lipopolysaccharide (LPS) treatment: $100 \mu \mathrm{L}$ of $0.1 \mathrm{mg} / \mathrm{mL}$ LTA from B. subtilis (Sigma, St. Louis) or ultra-pure LPS (contaminants $<0.3 \%$ ) (List Biological Laboratory, Campbell, CA) in antibiotic-free medium was added to the apical or basolateral cell culture compartment as indicated. For experiments in Figs. $(\mathbf{1}, \mathbf{2})$ measuring changes in expression or protein release, time points are as noted in figures or legends. For experiments in Fig. (3) using conditioned media, the media were collected from each compartment following a 24-hour incubation, centrifuged at
$10,000 \mathrm{~g}$ for 10 minutes and transferred to clean tubes. In some experiments collected media were frozen at $-20^{\circ} \mathrm{C}$ prior to analysis.

RNA harvest and semi-quantitative PCR. RNA was harvested from 4 transwells using RNeasy (Qiagen, Valencia, CA) protocol as directed by the manufacturer. cDNAs were made from up to $2 \mu \mathrm{g}$ total RNA, random hexamers and MLV-reverse transcriptase (Invitrogen, Carlsbad, CA). The cDNAs were subject to semiquantitative PCR with the following human primers: CCL20 forward GCA AGC AAC TTT GAC TGC TG and reverse ATT TGC GCA CAC AGA CAA CT; SLPI forward CCT GCC TTC ACC ATG AAG TCC AGC GGC and reverse CAT TTG ATG CCA CAA GTG TCA; Beta Defensin 2 forward CCT GAT GCC TCT TCC AGG TG and reverse GAG GGA GCC CTT TCT GAA TC; and GAPDH forward GGA CCT GAC CTG CCG TCT A and reverse TGC TGT AGC CAA ATT CGT TG. The PCR cycles were, for CCL20 and SLPI, $95^{\circ} \mathrm{C}$ for $2 \mathrm{~min}$, and 23 cycles of $94^{\circ} \mathrm{C}, 60^{\circ} \mathrm{C}, 72$ ${ }^{\circ} \mathrm{C} 30$ seconds each, followed by a 5 min $72{ }^{\circ} \mathrm{C}$ extension. Exceptions were, GAPDH was run for 19 cycles and for $\mathrm{HBD} 2$, the anneal temperature was $55^{\circ} \mathrm{C}$. In all cases the products were radio labeled in the final cycle by including 1 $\mu \mathrm{Ci} 32 \mathrm{P}-\mathrm{dCTP}$. The products were separated on a $5 \%$ polyacrylamide gel and quantitated on a Molecular Dynamic PhosphoImager.

ELISA for human CCL20. Collections of media from treated BEAS-2B cells were analyzed for human CCL20 with a commercially available ELISA kit (R\&D Systems, Minneapolis, MN) in 96-well Maxi-Sorp ELISA plates (NUNC, Rochester, NY) as previously described [36].

Bacterial survival assays. A sterile loop-full of laboratory strain of $E$. coli $(\mathrm{DH} 5 \alpha)$ was grown at $37^{\circ} \mathrm{C}$ in a shaking incubator overnight in $10 \mathrm{~mL}$ of antibiotic-free Luria Broth (LB). Following overnight incubation, the bacteria were resuspended in sterile water and serial dilutions were made. OD analysis was used to confirm initial bacterial counts and all final counts reported are the result of a minimum of triplicate plate counts for each treatment group. Using methods modified from Fahey and Wira (where a water wash of the apical surface of epithelial cells was collected) [37], conditioned media were collected from the apical surface of treated BEAS-2B cultures. A $100 \mu \mathrm{L}$ aliquot of bacterial suspension was mixed in microfuge tubes with an equal volume of the apical conditioned media or with controls as described. The mixture was then incubated for 30 minutes at room temperature (RT). After incubation, the mixtures were plated in triplicate on antibiotic-free LB agar plates and incubated for 18 -hour at $37^{\circ} \mathrm{C}$, after which colony-forming units (CFU) were counted.

Neutralization of antibacterial activity with antibody to hCCL20. Incubations of rabbit polyclonal anti-hCCL20 (Abcam Inc., Cambridge, MA) or normal rabbit IgG isotype control (R\&D Systems) with either apical media collections from TS- and LTA-treated cells or recombinant hCCL20 (R\&D Systems) were conducted for 60 minutes at RT. $5 \mu \mathrm{L}$ of $1.0 \mathrm{mg} / \mathrm{mL}$ anti-hCCL20, $45 \mu \mathrm{L}$ of sterile water, and 50 $\mu \mathrm{L}$ of media collected from treated cells or recombinant hCCL2 0 were incubated for 60 minutes at RT; $50 \mu \mathrm{L}$ of 1 $\mathrm{mg} / \mathrm{mL}$ normal rabbit $\mathrm{IgG}$ isotype control and $50 \mu \mathrm{L}$ of collected media or r-hCCL20 were incubated for the same 
$1 \mathrm{~A}$
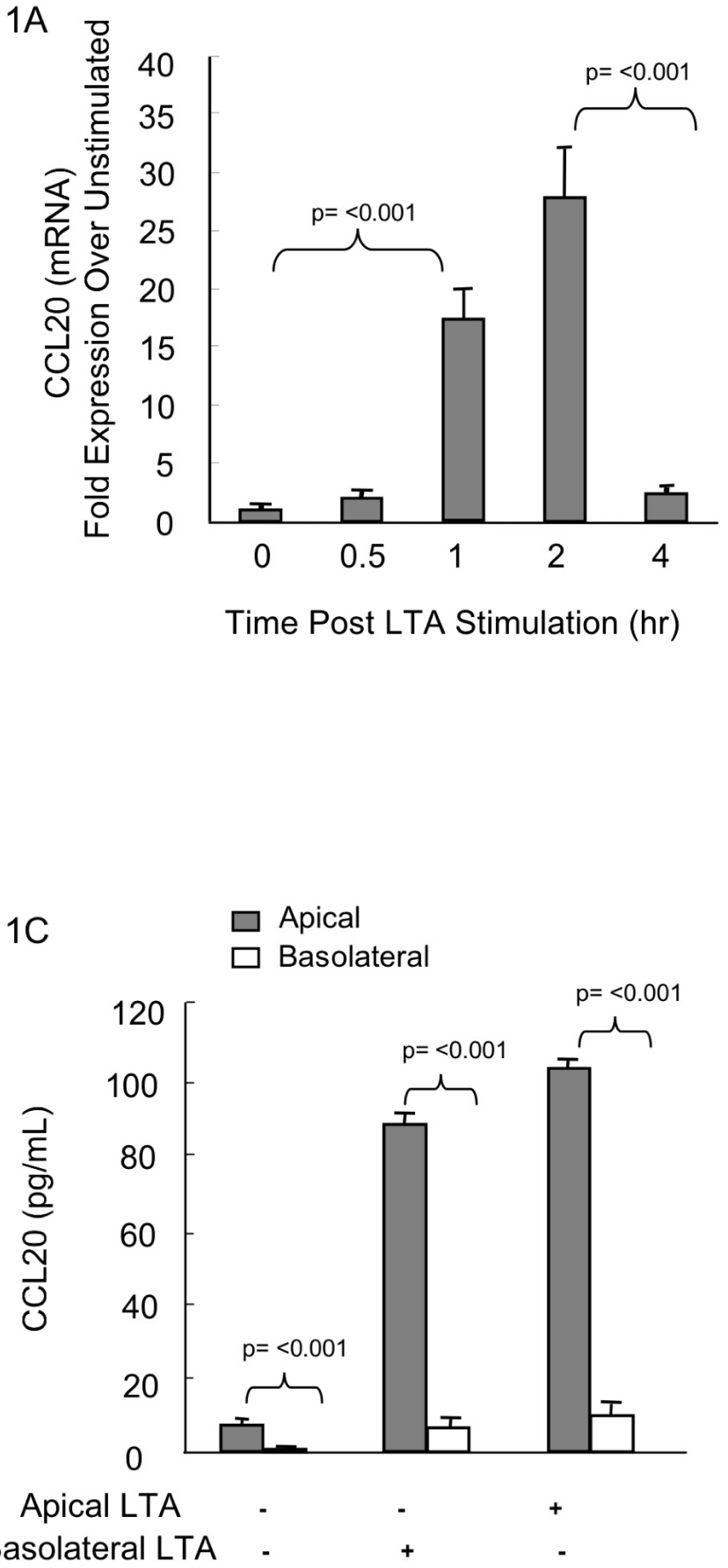

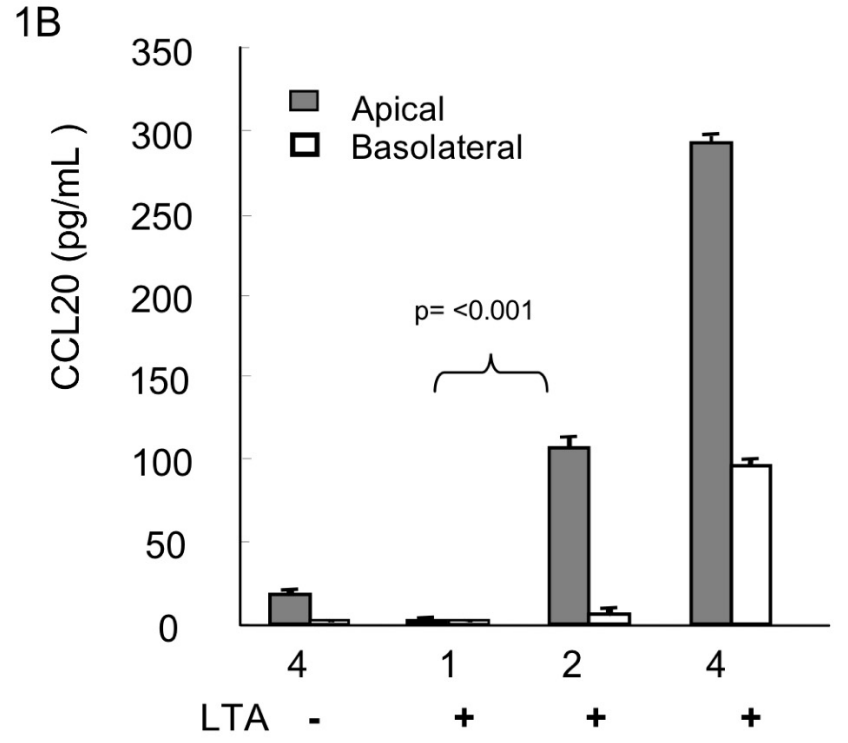

Time Post LTA Stimulation (hr)
1D

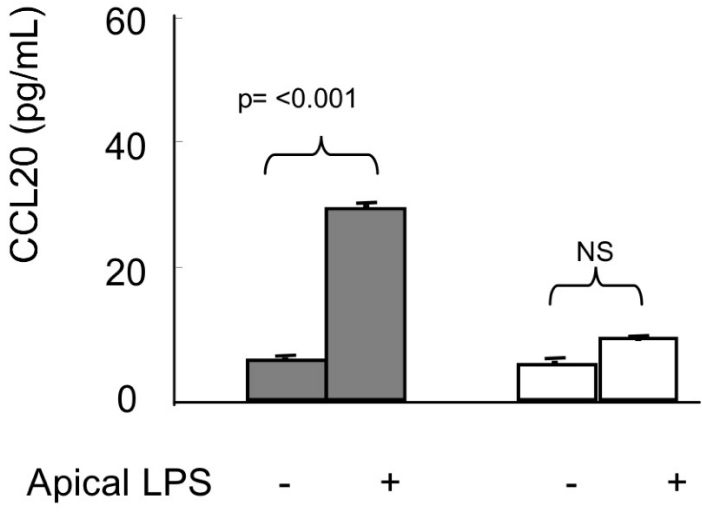

Fig. (1). BEAS-2B cells express and secrete CCL20 on a constitutive and stimulated basis. (A) Peak CCL20 mRNA accumulation occurs 2 hours after stimulation of BEAS-2B cells with LTA. Average CCL20 mRNA expression from three individual samples normalized to GAPDH mRNA expression. (B) CCL20 release occurs within 4 hours after apical stimulation with LTA; secretion of CCL20 is preferential to the apical compartment. (C) After 4 hours of LTA stimulation, regardless of apical or basolateral treatment, secretion of CCL20 is preferential to the apical compartment. (D) Following 4 hours stimulation with ultra-pure LPS, BEAS-2B cells produced increased apical secretion of CCL20 while change in basolateral secretions was not significant. Bars in each panel reflects values and variation of three or more individual samples. Panels $\mathbf{C}$ and $\mathbf{D}$ are representative of two or more experiments, each with three or more replicates of each treatment. Error bars represent standard deviation.

duration under the same conditions. These respective mixtures were then incubated with $100 \mu \mathrm{L}$ suspensions of $E$. coli and bacterial survival assays were conducted as described earlier.
Statistical analyses. ANOVA analyses using a Tukey post test were performed using In-Stat software. All error bars shown represent standard deviation. 


\section{RESULTS}

CCL20 Expression Peaks Rapidly Following LTA Stimulation with Release Directed Predominantly to the Apical/Luminal Compartment

Here, we investigated CCL20 patterns of expression and release in BEAS-2B, a human bronchial epithelial cell line. Time course studies of the expression and release of CCL20 in BEAS-2B in response to LTA stimulation demonstrate a rapid increase in both gene expression and protein release. As seen in Fig. (1A), following treatment of BEAS-2B cells with LTA, expression peaks approximately two hours after stimulation with subsequent increasing protein release through a four hour time point (Fig. 1B). CCL20 expression and release is upregulated in response to the TLR ligand LTA (Fig. 1C). Irrespective of whether the cell cultures are exposed to LTA treatment in the apical or basolateral compartment, CCL20 is released preferentially to the apical/luminal compartment (Fig. 1C). Studies using ultra pure LPS that were similar in design to those shown where LTA was used as a TLR agonist, were also conducted (not shown). The overall pattern of response was similar to the pattern of response seen in our LTA studies. However, as seen in Fig. (1D), ultra pure LPS stimulation elicited a less robust response.

CS exposure suppresses expression and release of CCL20. Polarized BEAS-2B cells, grown on cell culture inserts, constitutively express (Fig. 2A, B) and release CCL20 (Fig. 1C, 2C). To test the effect of cigarette smoke exposure in vitro, polarized BEAS-2B cells were exposed to cigarette smoke extract (CSE). CSE was prepared using a modified method of Carp and Janoff (see methods) [35]. When bronchial epithelial cells were pretreated with CSE, rinsed twice with PBS and then challenged apically with LTA, both CCL20 mRNA expression (2A and 2B) and the release of CCL20 protein (2C) were significantly decreased compared to PBS and LTA treated controls. We used treatment conditions (see methods) developed to maintain cell viability and metabolism as is evident by expression of GAPDH (Fig. 2A) in CSE treated cultures. In serial dilution studies of the effect of CSE on BEAS-2B cell culture response to LTA stimulation, the levels of CCL20 suppression was dose dependent (Fig. 2D).

Expression of two other antimicrobial peptides, SLPI and beta-defensin 2 (hBD2) were assessed (Fig. 2A). SLPI was previously reported to be produced by BEAS-2B cells [38] and low levels of expression were detected, but no evidence of hBD2 expression was found. Change in SLPI expression from CSE exposure did not reach a significant level in these cell cultures.

Cigarette smoke exposure attenuates antimicrobial activity of apical secretions of BEAS-2B cells. Antimicrobial activity of apical secretions of LTA stimulated BEAS-2B cells was consistent and statistically significant (Fig. 3A). In support of our hypothesis, when BEAS-2B cells were treated with CSE, little to no detectable antimicrobial activity was seen in the apical secretions (Fig. 3A). The antimicrobial activity of recombinant human CCL20 is demonstrated in Fig. (3B). The range of CCL20 tested extends beyond the range of average levels measured in bronchial lavage fluid in normal subjects $(10.4 \mathrm{pg} / \mathrm{mL})$ and in patients with cystic fibrosis patients $(907 \mathrm{pg} / \mathrm{mL})$ [27].

When apical media from BEAS-2B cell cultures were treated with neutralizing antibodies, antimicrobial activity was abolished demonstrating a prominent antimicrobial role for CCL20 in this system (Fig. 3C). The effect of the antiCCL20 on antimicrobial activity is similar to treatment of the cells with CSE. Both treatments virtually eliminate the bactericidal activity.

\section{DISCUSSION}

The release of antimicrobial secretions by mucosal epithelial cells is likely a crucial aspect of maintaining a balance between mammals and their endemic flora [39]. Rapid PRR-medicated activation of antimicrobial secretions in response to imbalances in flora is also necessary to defend against infection $[40,41]$. The observation that CS exposure increases the susceptibility to infection led us to test if CS exposure would suppress generation of antimicrobial activity in general from airway epithelial cells as well as to impact CCL20 specifically. These studies support the hypothesis that one mechanism whereby CS exposure may cause increased susceptibility to infection is through reduced release of antimicrobial peptides.

The time course of CCL20 release has important functional implications. In the system used here, the time course of induction of CCL20 by TLR agonists is both rapid and transient and this correlates with our previous studies on CCL20 release from rat uterine epithelial cells [42]. Rapid induction is likely important for both its role as a direct antimicrobial and for its role as a chemokine. In contrast, sustained high levels of CCL20 could be deleterious, possibly generating conditions that favor autoimmunity or hypersensitivity or by upsetting the normal balance of microbial flora found on mucosal surfaces.

Depending on conditions, the dominant release of CCL20 can occur either apically or basolaterally and, like the time course of release, this balance is likely to affect the impact CCL20 has as a direct antimicrobial versus that of a chemokine. Apical release suggests a potentially high impact role in killing or attenuating microbes at the mucosal interface. Interestingly, apical release of CCL20 in response to a TLR agonist is not universal. For example in response to the TLR7 and TLR9 agonists, loxoribin and bacterial DNA $\mathrm{CpG}$ motif respectively, we have previously shown that CCL20 is released preferentially to the basolateral compartment by mouse uterine epithelial cells [43]. It has also been demonstrated that basolateral treatment of human airway epithelial cells with IL-17 results in a significant shift with primarily basolateral release of CCL20 [44]. Together these observations suggest that CCL20 is a precisely regulated antimicrobial and chemotactic peptide. It is likely that this regulation is important in the overall immune effects of CCL20.

Our results appear to contrast with data from a recent chronic obstructive pulmonary disease (COPD) model study showing that protein levels of CCL20 were increased in bronchoalveolar lavage obtained from CS exposed mice (Bracke, et al. 2006) [29]. While the difference could be species associated, it is more likely that it reflects differences seen when stimulating a pure epithelial cell culture in vitro 
$2 A$

CCL20

N

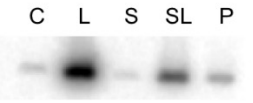

$\underline{\text { SLPI }}$

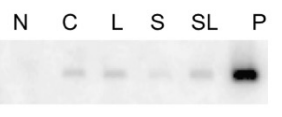

$\underline{\text { hBD2 }}$

$\begin{array}{llllllllll}N & C & L & S & S L & P\end{array}$
GAPDH

$\begin{array}{llllllllllllll}N & C & L & S & S L & P\end{array}$
2B

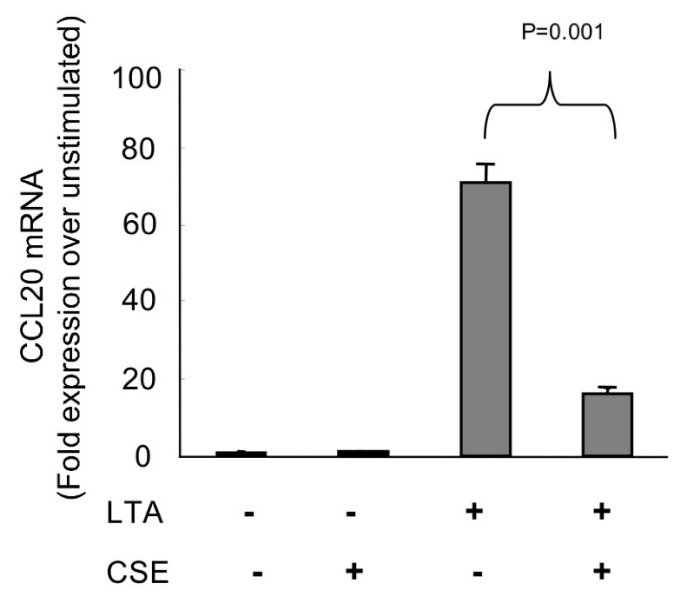

2D

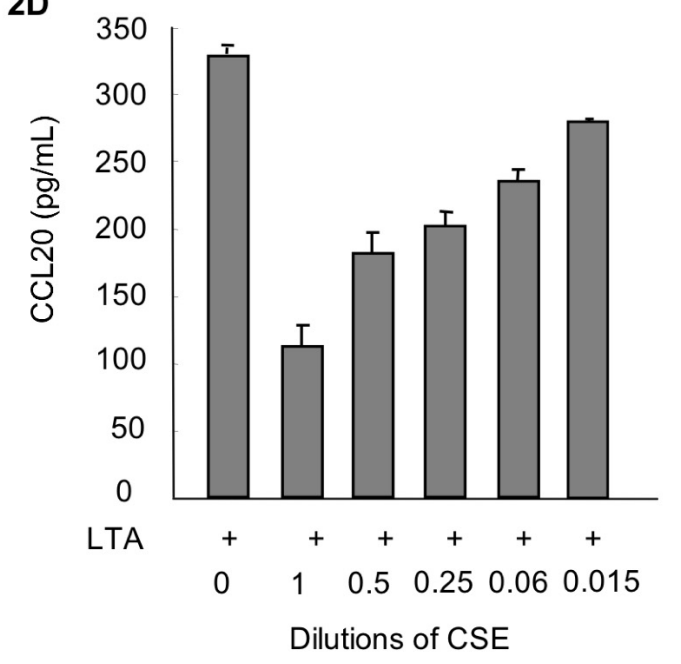

$2 C$

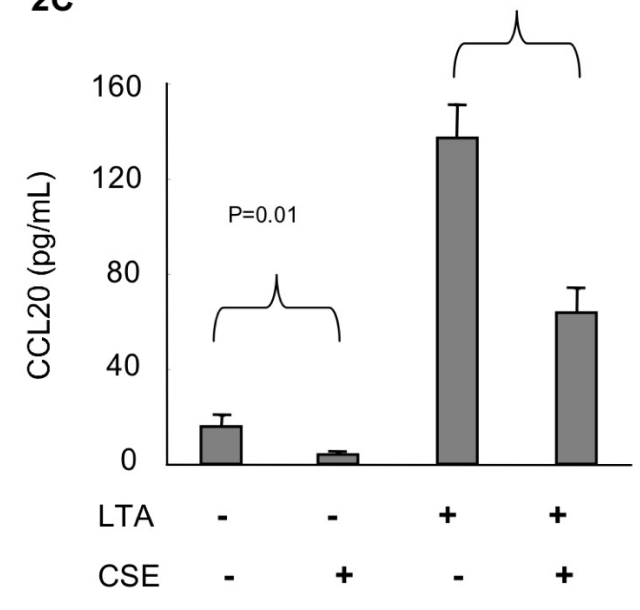

Fig. (2). Cigarette smoke extract suppresses CCL20 expression and release. (A) Phosphoimage of radiolabeled RT-PCR showing expression of CCL20, SLPI, hBD2 and GAPDH, two hours after LTA or carrier treatment. Specific conditions for each column are as follows: "N" is no reverse transcriptase; "C" is constitutive (non-stimulated) expression; "L" is LTA-stimulated; "S" is smoke-exposed, non-stimulated; "SL" is smoke-exposed, LTA-stimulated; and "P" is positive control RNA from uterine tissue. (B) Exposure of BEAS-2B cells to CSE results in significant reduction of LTA-stimulated CCL20 mRNA. (C) Exposure of BEAS-2B cells to CSE results in a reduction of constitutive and LTA-stimulated CCL20 peptide release. (D) CSE treatment of Beas-2b cells resulted in a dose dependent reduction in response to LTA. Panels A and B relate to studies done two hours after apical LTA or carrier treatment. Bars in panel B represent the average of three reactions with all values normalized to expression of GAPDH. Panels $\mathbf{C}$ and D present studies done after 4 hours exposure to apical LTA treatment and each are representative of results from 2 or more separate experiments each with 4 to 6 replicates of each treatment.

as opposed to the more complex in vivo environment. The increased levels of CCL20 reported in Bracke, et al. 2006 could originate from leukocytes secretions induced due to inflammation caused by CS or by low levels of infection. Results suggesting that CCL20 expression and release were abnormal under CS exposure conditions are important to both the Bracke study and to the research reported here. The findings suggest that more work is needed to better understand the complex effects of CS on the development of precursor conditions that lead to lethal pathologies. 
$3 A$

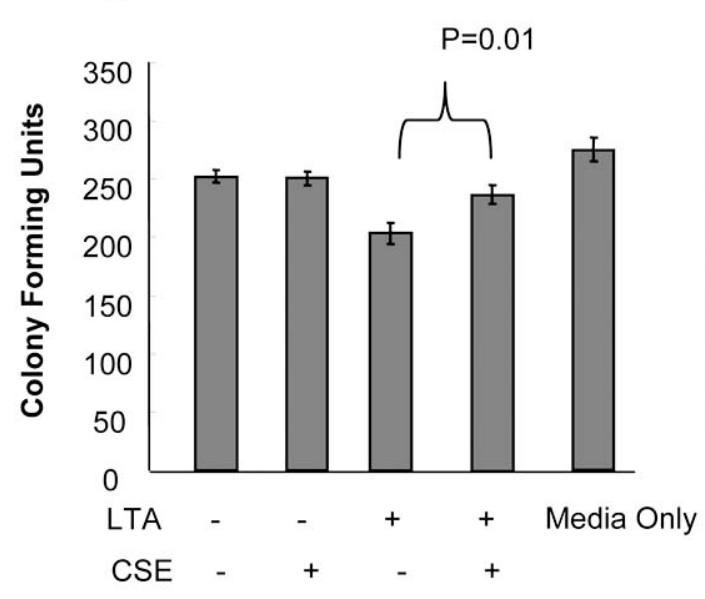

3B

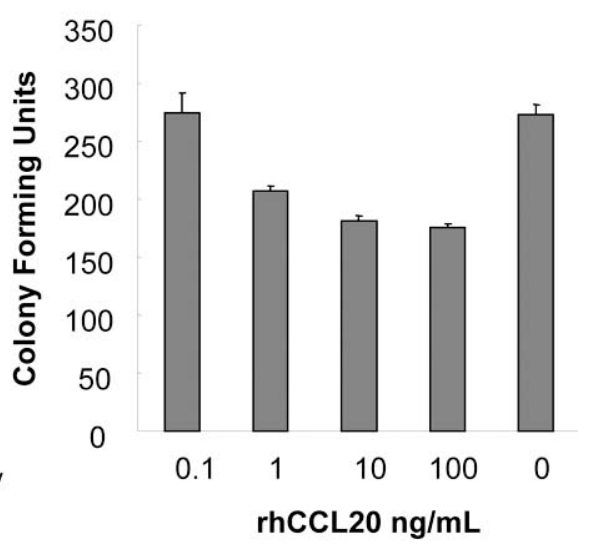

$3 \mathrm{C}$

Apical Conditioned Media

Isotype Antibody

CCL20 Neutralizing Antibody

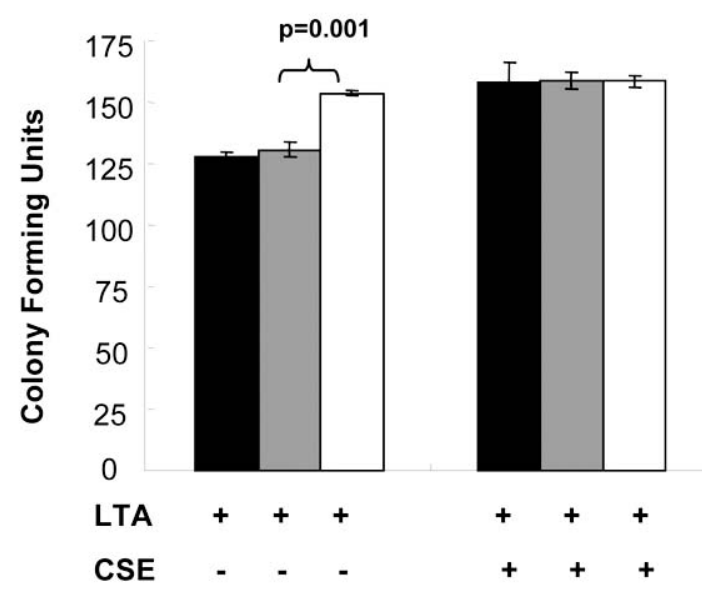

Fig. (3). CS exposure inhibits the antimicrobial properties of CCL20. Following treatment with CSE for 90 minutes and of controls with carrier, Beas-2B cells were treated apically with LTA or media only and cultured in antibiotic free DMEM-F12 for 24 hrs. E coli were treated with apical media for $30 \mathrm{~min}$ at RT and then plated in triplicate. (A) Media from CS-exposed, LTA-stimulated BEAS-2B cells has decreased bactericidal activity. Results for each treatment are representative of the results from seven separate experiments, $(\mathrm{p}<0.01)$ LTA pretreated with smoke different from LTA treatment. (B) Recombinant human CCL20 is bactericidal in a dose-dependent manner. Each bar represents data collected in triplicate. (C) CCL20-specific neutralizing antibody eliminates antimicrobial activity of the apical secretions of LTA stimulated cells. Neutralizing antibody results are representative of two independent experiments with three or more plates per treatment, $(\mathrm{p},<0.001)$ CCL20 neutralizing antibody different from apical conditioned media.

Interestingly, using doses that spanned beyond the known range of human airway CCL20 release $(10.4 \mathrm{pg} / \mathrm{mL}$ in normal subjects to $907 \mathrm{pg} / \mathrm{mL}$ in patients with cystic fibrosis) [27], bacterial growth was consistently suppressed but not eliminated in the laboratory strain of $E$. coli used in our studies. While in medicine the goal of antimicrobial treatment is frequently the elimination of an offending microbe, here a consistent but more subtle effect is demonstrated. This occurs in the context of CCL20's chemotactic activity for cells carrying the CCR6 receptor
[19]. This chemotactic activity attracts effector/memory B cells and $T$ cells as well as immature dendritic cells to the site of CCL20 release. The presence of these cells is crucial to conditions that allow for initiation of a response by the adaptive immune system. While the direct antimicrobial activity of CCL20 is broad, and includes Gram positive and Gram negative bacteria, yeast [27] and some viruses [28], it seems likely that the broad antimicrobial and chemotactic activity act in concert under normal conditions to respond to the ever changing environment at the mucosa. 


\section{CONCLUSION}

This report expands the understanding of CCL20 regulation and establishes an impact of CS on aberrant production of CCL20 and its activity as an antimicrobial peptide. If the hypothesis proposed here is correct, a suppression of CCL20 and its antimicrobial activity in CS exposed individuals may enhance susceptibility to infections. CS is a complex mixture and has many biological activities. While suppression of CCL20 production by CS provides insight into one specific mechanism whereby CS exposure may diminish antimicrobial protection, additional studies are needed to better understand the effects of this and other environmental pollutants on functions of the innate immune system.

\section{ACKNOWLEDGEMENT}

We gratefully acknowledge the Flight Attendant Medical Research Institute (FAMRI) for support of this research.

\section{ABBREVIATIONS}

$\begin{array}{ll}\text { ALTE } & =\text { Acute life threatening events } \\ \text { BCM } & =\text { Beas-2B-conditioned media } \\ \text { BEAS-2B } & =\text { Human airway epithelial cell line } \\ \text { CCL20 } & =\text { Chemokine ligand } 20 \\ \text { CFU } & =\text { Colony forming units } \\ \text { COPD } & =\text { Chronic obstructive pulmonary disease } \\ \text { CS } & =\text { Cigarette smoke } \\ \text { CSE } & =\text { Cigarette smoke extract } \\ \text { HPV } & =\text { Human papillomavirus } \\ \text { hBD2 } & =\text { Human beta-defensin } 2 \\ \text { IBD } & =\text { Inflammatory bowel disease } \\ \text { IMD } & =\text { Invasive meningococcal disease } \\ \text { LB } & =\text { Luria Broth } \\ \text { LPS } & =\text { Lipopolysaccharide } \\ \text { LTA } & =\text { Lipoteichoic acid } \\ \text { PRR } & =\text { Pattern recognition receptors } \\ \text { RT } & =\text { Room temperature } \\ \text { SIDS } & =\text { Sudden infant death syndrome } \\ \text { SLPI } & =\text { Secretory leukoprotease inhibitor } \\ \text { TLR } & =\text { Toll-like receptor } \\ & \end{array}$

\section{REFERENCES}

[1] Arcavi L, Benowitz NL. Cigarette smoking and infection. Arch Intern Med 2004; 164(20): 2206-16.

[2] Drannik AG, Pouladi MA, Robbins CS, Goncharova SI, Kianpour $\mathrm{S}$, Stampfli MR. Impact of cigarette smoke on clearance and inflammation after Pseudomonas aeruginosa infection. Am J Respir Crit Care Med 2004; 170(11): 1164-71.

[3] Pirogowicz I, Bujnowska-Fedak M, Piorek M, Steciwko A. [Effect of passive cigarette smoking on the frequency of respiratory tract infections, allergy and bronchial asthma in children]. Przegl Lek 2004; 61(10): 1061-4.

[4] Bradley JP, Bacharier LB, Bonfiglio J, et al. Severity of respiratory syncytial virus bronchiolitis is affected by cigarette smoke exposure and atopy. Pediatrics 2005; 115(1): e 7-14.
Gleeson M, Clancy RL, Cox AJ, Gulliver SA, Hall ST, Cooper DM. Mucosal immune responses to infections in infants with acute life threatening events classified as 'near-miss' sudden infant death syndrome. FEMS Immunol Med Microbiol 2004; 42(1): 105-18.

[6] Gryczynska D, Kobos J, Zakrzewska A. Relationship between passive smoking, recurrent respiratory tract infections and otitis media in children. Int J Pediatr Otorhinolaryngol 1999; 49(Suppl 1): $\mathrm{S} 275-8$

[7] McCall BJ, Neill AS, Young MM. Risk factors for invasive meningococcal disease in southern Queensland, 2000-2001. Intern Med J 2004; 34(8): 464-8.

[8] Thorsen P, Vogel I, Molsted K, et al. Risk factors for bacterial vaginosis in pregnancy: a population-based study on Danish women. Acta Obstet Gynecol Scand 2006; 85(8): 906-11.

[9] Silverberg MJ, Schneider MF, Silver B, et al. Serological detection of human papillomavirus type 16 infection in human immunodeficiency virus (HIV)-positive and high-risk HIVnegative women. Clin Vaccine Immunol 2006; 13(4): 511-9.

[10] Heffner LJ, Sherman CB, Speizer FE, Weiss ST. Clinical and environmental predictors of preterm labor. Obstet Gynecol 1993; 81(5 Pt 1): 750-7.

[11] McPheeters ML, Miller WC, Hartmann KE, et al. The epidemiology of threatened preterm labor: a prospective cohort study. Am J Obstet Gynecol 2005; 192(4): 1325-9; discussion 9-30.

[12] Saint S, Kaufman SR, Rogers MA, Baker PD, Boyko EJ, Lipsky BA. Risk factors for nosocomial urinary tract-related bacteremia: a case-control study. Am J Infect Control 2006; 34(7): 401-7.

[13] Male D, Brostoff J, Roth DB, Roitt I. Immunology 7th ed. Mosby: Elsevier 2006.

[14] Janeway CA Jr, Medzhitov R. Introduction: the role of innate immunity in the adaptive immune response. Semin Immunol 1998; 10(5): 349-50

[15] Ganz T, Lehrer RI. Antibiotic peptides from higher eukaryotes: biology and applications. Mol Med Today 1999; 5(7): 292-7.

[16] Schutte BC, McCray PB, Jr. [beta]-defensins in lung host defense. Annu Rev Physiol 2002; 64: 709-48.

[17] Hooper LV, Stappenbeck TS, Hong CV, Gordon JI. Angiogenins: a new class of microbicidal proteins involved in innate immunity. Nat Immunol 2003; 4(3): 269-73.

[18] Pasare C, Medzhitov R. Toll-like receptors and acquired immunity. Semin Immunol 2004; 16(1): 23-6.

[19] Schutyser E, Struyf S, Van Damme J. The CC chemokine CCL20 and its receptor CCR6. Cytokine Growth Factor Rev 2003; 14(5): 409-26.

[20] Kwon JH, Keates S, Bassani L, Mayer LF, Keates AC. Colonic epithelial cells are a major site of macrophage inflammatory protein 3alpha (MIP-3alpha) production in normal colon and inflammatory bowel disease. Gut 2002; 51(6): 818-26.

[21] Reibman J, Hsu Y, Chen LC, Bleck B, Gordon T. Airway epithelial cells release MIP-3alpha/CCL20 in response to cytokines and ambient particulate matter. Am J Respir Cell Mol Biol 2003; 28(6): 648-54.

[22] Crane-Godreau MA, Wira CR. Effect of Escherichia coli and Lactobacillus rhamnosus on macrophage inflammatory protein 3 alpha, tumor necrosis factor alpha, and transforming growth factor beta release by polarized rat uterine epithelial cells in culture Infect Immun 2004; 72(4): 1866-73.

[23] Krzysiek R, Lefevre EA, Bernard J, et al. Regulation of CCR6 chemokine receptor expression and responsiveness to macrophage inflammatory protein-3alpha/CCL20 in human B cells. Blood 2000; 96(7): 2338-45.

[24] Dieu MC, Vanbervliet B, Vicari A, Bridon JM, Oldham E, AitYahia $\mathrm{S}$, et al. Selective recruitment of immature and mature dendritic cells by distinct chemokines expressed in different anatomic sites. J Exp Med 1998; 188(2): 373-86.

[25] Campbell JJ, Hedrick J, Zlotnik A, Siani MA, Thompson DA, Butcher EC. Chemokines and the arrest of lymphocytes rolling under flow conditions. Science 1998; 279(5349): 381-4.

[26] Yang D, Chen Q, Hoover DM, et al. Many chemokines including CCL20/MIP-3alpha display antimicrobial activity. J Leukoc Biol 2003; 74(3): 448-55

[27] Starner TD, Barker CK, Jia HP, Kang Y, McCray PB, Jr. CCL20 is an inducible product of human airway epithelia with innate immune properties. Am J Respir Cell Mol Biol 2003; 29(5): 62733. 
[28] Kim BE, Leung DY, Streib JE, Boguniewicz M, Hamid QA, Howell MD. Macrophage inflammatory protein 3alpha deficiency in atopic dermatitis skin and role in innate immune response to vaccinia virus. J Allergy Clin Immunol 2007; 119(2): 457-63.

[29] Bracke KR, D'Hulst AI, Maes T, et al. Cigarette smoke-induced pulmonary inflammation and emphysema are attenuated in CCR6deficient mice. J Immunol 2006; 177(7): 4350-9.

[30] Kaser A, Ludwiczek O, Holzmann S, et al. Increased expression of CCL20 in human inflammatory bowel disease. J Clin Immunol 2004; 24(1): 74-85.

[31] Homey B, Dieu-Nosjean MC, Wiesenborn A, et al. Up-regulation of macrophage inflammatory protein-3 alpha/CCL20 and CC chemokine receptor 6 in psoriasis. J Immunol 2000; 164(12): 662132.

[32] Jindal SK, Aggarwal AN, Chaudhry K, et al. A multicentric study on epidemiology of chronic obstructive pulmonary disease and its relationship with tobacco smoking and environmental tobacco smoke exposure. Indian J Chest Dis Allied Sci 2006; 48(1): 23-9.

[33] Lashner BA, Shaheen NJ, Hanauer SB, Kirschner BS. Passive smoking is associated with an increased risk of developing inflammatory bowel disease in children. Am J Gastroenterol 1993; 88(3): 356-9.

[34] Behnam SM, Behnam SE, Koo JY. Smoking and psoriasis. Skinmed 2005; 4(3): 174-6.

[35] Carp H, Janoff A. Possible mechanisms of emphysema in smokers. In vitro suppression of serum elastase-inhibitory capacity by fresh cigarette smoke and its prevention by antioxidants. Am Rev Respir Dis $1978 ; 118(3)$ : 617-21.

[36] Crane-Godreau MA, Wira CR. Effects of Estradiol on Lipopolysaccharide and Pam3Cys Stimulation of CCL20/Macrophage Inflammatory Protein 3 Alpha and Tumor Necrosis Factor Alpha Production by Uterine Epithelial Cells in Culture. Infect Immun 2005 73(7): 4231-7.
[37] Fahey JV, Wira CR. Effect of menstrual status on antibacterial activity and secretory leukocyte protease inhibitor production by human uterine epithelial cells in culture. J Infect Dis 2002; 185(11): 1606-13.

[38] Jaumann F, Elssner A, Mazur G, Dobmann S, Vogelmeier C. Transforming growth factor-beta1 is a potent inhibitor of secretory leukoprotease inhibitor expression in a bronchial epithelial cell line. Munich Lung Transplant Group. Eur Respir J 2000; 15(6): 1052-7.

[39] Meyer-Hoffert U, Hornef MW, Henriques-Normark B, et al. Secreted enteric antimicrobial activity localizes to the mucus surface layer. Gut 2008; 57(6): 764-71.

[40] Qureshi ST, Medzhitov R. Toll-like receptors and their role in experimental models of microbial infection. Genes Immun 2003; 4(2): 87-94.

[41] Gallo RL, Murakami M, Ohtake T, Zaiou M. Biology and clinical relevance of naturally occurring antimicrobial peptides. J Allergy Clin Immunol 2002; 110(6): 823-31.

[42] Crane-Godreau MA, Wira CR. CCL20/macrophage inflammatory protein 3alpha and tumor necrosis factor alpha production by primary uterine epithelial cells in response to treatment with lipopolysaccharide or Pam3Cys. Infect Immun 2005; 73(1): 47684.

[43] Soboll G, Crane-Godreau MA, Lyimo MA, Wira CR. Effect of oestradiol on PAMP-mediated CCL20/MIP-3 alpha production by mouse uterine epithelial cells in culture. Immunology 2006; 118(2): 185-94.

[44] Kao CY, Huang F, Chen Y, et al. Up-regulation of CC chemokine ligand 20 expression in human airway epithelium by IL-17 through a JAK-independent but MEK/NF-kappaB-dependent signaling pathway. J Immunol 2005; 175(10): 6676-85.

(C) Crane-Godreau et al.; Licensee Bentham Open .

This is an open access article licensed under the terms of the Creative Commons Attribution Non-Commercial License (http://creativecommons.org/licenses/by$\mathrm{nc} / 3.0 /$ ) which permits unrestricted, non-commercial use, distribution and reproduction in any medium, provided the work is properly cited. 